\title{
Entre política y religión a fines del siglo XVII. Prácticas y discursos cruzados
}

\author{
María Luz GonzÁlez MezQuita \\ Universidad Nacional de Mar del Plata \\ gonmez@hotmail.com
}

Recibido: 26 de julio de 2012

Aceptado: 9 de octubre de 2014

\begin{abstract}
RESUMEN
La sucesión de Carlos II plantea un interesante campo para el estudio sociocultural de la política a propósito del cruce de intereses de las facciones que se enfrentan en la corte madrileña con motivo de la sucesión del monarca. En este trabajo se propone analizar -en el contexto de la cuestión sucesoria que precede a la Guerra de Sucesión Española- no sólo el ya reconocido ascendiente que la opinión del clero tenía en la sociedad, sino las prácticas y discursos usados desde el campo político y el religioso y cómo se cruzan y se convierten en instrumentos para manifestar las posiciones que defendían los derechos de Austrias o Borbones. Al mismo tiempo, se intenta destacar la intersección de las atribuciones jurisdiccionales con trasfondo regalista que se enfrentan en este conflicto.
\end{abstract}

Palabras clave: Carlos II, Austrias, Borbones, política, religión, regalismo.

\section{Between Politics and Religion at the end of the Seventeenth Century. Crossed Practices and Discourses}

\begin{abstract}
The succession of Charles II proposes an interesting field for the socio-cultural study of the politics aiming to the crossing interests of the factions that match up the court of Madrid due to the monarch's succession. The aim of this work is to analyze - in the context of the succession issue that precedes the War of the Spanish Succession - not only the already recognized influence that the clergy opinion had in the society, but the practices and discourses used in the political field and the religious one, and how they crossed and became instruments to state the positions that defended the rights of Habsburgs or Bourbons. Furthermore, this work tries to emphasize the intersection of the jurisdictional attributions with regalist background that are confronted in this conflict.
\end{abstract}

Key words: Charles II of Spain, Habsburgs, Bourbons, Politics, Religion, Regalism. 
"Confieso que algunas veces me he puesto a considerar ¿a quién debemos mas los Españoles si a los señores Reyes Católicos que discurrieron y fundaron este propugnáculo de fe, o al señor don Felipe $\mathrm{V}$ que le conservó y mantuvo quando se hallaba combatido de freqüentes y caseras sujestiones, para totalmente derribarlo"

Proceso criminal, p. 218

La guerra es un tiempo en el que se potencian los conflictos de una sociedad. En el caso de la guerra de Sucesión Española, el enfrentamiento puso de manifiesto el cruce de intereses de las facciones que se habían generado en los últimos años del reinado de Carlos II a propósito del tema de la sucesión del monarca' . "La lucha por el poder que constituye el telón de fondo del reinado de Carlos II resulta ser, historiográficamente hablando, una de las manifestaciones más claras de la llamada decadencia española, si bien este concepto hoy está siendo objeto de muchas matizaciones"2.

Proponemos reconsiderar este momento a través del estudio de los discursos ${ }^{3}$ y las prácticas que se producen, para aproximarnos a las representaciones en las que confluyen y se intersectan en planos múltiples ${ }^{4}$. Intentamos subrayar la importancia de pensar las relaciones entre política y religión en el cambio de siglo a partir de este enfoque $^{5}$. Los vínculos entre estos dos campos de poder no pueden estar ausentes a la hora de analizar las diferentes variables de los procesos históricos en el Antiguo Régimen, dado que la religión impregnaba todos sus ámbitos. ${ }^{6}$ En la España del siglo XVII sociedad, iglesia y poder político "se hallaban profundamente imbricados y

1 Un interesante análisis sobre el tema, con actualizada bibliografía, en: Fernández Albaladejo, P.: La crisis de la Monarquía. Historia de España de Fontana, J. y Villares, R. (dirs.), vol. 4. Barcelona, CríticaMarcial Pons, 2009. Sobre las discusiones en torno al reinado de Carlos II y del concepto de "decadencia", vid. GonzÁlez Mezquita, M. L.: Oposición y disidencia nobiliaria en la Guerra de Sucesión Española. El caso del Almirante de Castilla, Valladolid, Junta de Castilla y León, 2007. También vid. ArAndA PÉrez, F. J. (coord.): La declinación de la Monarquía Hispánica. V. I, Actas de la VII Reunión Científica de la Fundación Española de Historia Moderna (celebrada en Ciudad Real los días 3-6 de junio de 2002), Cuenca, Universidad de Castilla-La Mancha, 2004.

2 López-Cordón, M. V.: "Mujer, poder y apariencia o las vicisitudes de una regencia", Studia Historica, Historia Moderna, 19 (1998), pp. 49-66.

3 Entendemos por discurso el análisis de la realidad en diferentes niveles: ¿Cómo es la realidad? ¿Cómo se ve la realidad? ¿Cómo se distorsiona esa realidad a través de una mirada interesada? ¿Cómo se elaboró esa realidad? Esto es, cómo se llega "al producto reflexivo, deliberado e intencional por el que elaboramos nuestra visión de la realidad con arreglo a nuestros deseos e intereses....en definitiva, el análisis del discurso procuraría distinguir la visión simple de la realidad, la visión asumida inconscientemente por el sujeto de la realidad, la visión construida y proyectada hacia el exterior con unas necesidades, deseos y fines sociales". CASTRO CUENCA, J. y Aranda PÉREZ, J.: "El análisis del discurso. Una metodología para el estudio de la Historia social de la Edad Moderna", en CAstillo, S. (coord.): La Historia Social en España, Madrid, Siglo XXI, 1991, pp. 65-87.

4 Werner, M. y Zimermann, B.: "Penser l'histoire croisée: entre empirie et réflexivité", Annales HSS, janvier-février (2003), 58, 1, pp. 7-36.

5 Un estado de la cuestión sobre las relaciones entre lo político y lo religioso en Manuscrits, 20 (2002), número monográfico: "Les relacions Església-Estat durant 1'època de la Il-lustració”. Monod, P. K.: El poder de los reyes. Monarquía y religión en Europa, 1589-1715, Madrid, Alianza, 2001. Bergin, J.: Crown, Church and Episcopate, New Haven, Yale University, 2004.

6 Maravall, J. A.: La cultura del Barroco, Barcelona, Ariel, 1986. Seguí Cantos, J.: "Poder político, Iglesia y cultura en Valencia (1545-1611)", Estudis, 17 (1991), pp. 199-212, p. 199. Morgado GARCíA, A.: "Domínguez Ortiz y el clero en la España moderna" Historia Social, 47 (2003), pp. 29-53. 
creaban una cultura de la que resulta difícil separar lo que era religión y lo que era política"7

El clero tenía una posición preeminente a causa de la influencia política e ideológica del estamento, de su poder económico y de sus privilegios ante la ley. La religión proporcionaba un marco discursivo que se podía utilizar con distintos intereses. El cruce de los argumentos religiosos y políticos producía poder y puede afirmarse que en el caso del catolicismo el impacto no derivaría sólo de la especificidad del discurso sino también de la fuerza de la que disponía para crear una imagen del mundo. ${ }^{8}$ "La corte se presentó como un foco de atracción para un sinnúmero de religiosos que coparon las capillas reales y que a través del púlpito o el confesionario logaron ejercer una gran influencia, al actual no sólo como rectores espirituales, sino como consejeros políticos"9.

Los clérigos predicaban alabando la justicia del rey, bendecían sus ejércitos y lo sacralizaban ${ }^{10}$. No sorprende, por lo tanto, el hecho de que los monarcas aspiraran a tener a la Iglesia bajo su dominio. Sin embargo, eran frecuentes los conflictos que de manera más o menos evidente, enfrentaron a ambos campos de poder ${ }^{11}$. Abundan las manifestaciones de la publicística $y$, dentro de ella, de la sátira política ${ }^{12}$ que construyeron auténticas redes textuales. En este sentido, los episodios referidos a los "hechizos" del rey a fines del siglo XVII, en el marco de la indefinición sucesoria, conforman un complejo contexto que es objeto de un relato ${ }^{13}$ anónimo que los ana-

7 RuIz Rodríguez, J. I.: "La Villa de Madrid en el siglo XVII: Un mundo de complejas prácticas religiosas", Torre de los Lujanes, 61 (2002), pp 43-53.

8 Sobre la utilización de los recursos de la oratoria sagrada, vid. Álvarez-Ossorio Alvariño, A.: "La sacralización de la monarquía en el púlpito de la Capilla Real en tiempos de Carlos II". Criticón, 84-85 (2002), pp. 313-332. Del mismo autor "Facciones cortesanas y arte del buen gobierno en los sermones predicados en la Capilla Real en tiempos de Carlos II”, Criticón, 90 (2004), pp. 99-123.

9 López Arandia, M. A.: "Un criado muy antiguo de la Real Casa. La orden dominicana en el confesionario de Carlos II”, Magina, 13 (2009), pp. 113-158.

10 Para la guerra que precede a la llegada de los Reyes Católicos al trono, contexto similar en algunos aspectos, al que estamos analizando, NieTo Soria, J. M.: "Los fundamentos ideológicos del poder regio". VAldeón BAruque, J. (ed.): Isabel la Católica y la política, Valladolid, Ámbito, 2001, pp. 181-216. Nos hemos ocupado de la comparación entre las campañas de propaganda en ambas guerras en GonZALEZ MEZQUITA, M. L.: "Propaganda y legitimación en las crónicas de dos reinados: Isabel I y Felipe V" En: RiBOt, L., VALDEÓN BARUQue, J. y MAZA, E. (coords.): Isabel la Católica y su época, Valladolid, Instituto Universitario de Historia Simancas, Universidad de Valladolid, 2007, vol. I, pp. 361-384.

11 Morgado García, A.: Ser clérigo en la España del Antiguo Régimen, Cádiz. Universidad de Cádiz, 2000, p. 101. Sobre el papel del púlpito y el confesionario para inclinar voluntades, vid. Hale, J.: "War and public opinion in the fifteenth and sixteenth centuries", Past and Present, 22 (1961), pp. 3-35.

12 Vid. EgIdo, T.: Sátiras políticas de la España Moderna, Madrid, Alianza, 1973. Gómez-CEnTURIón JimÉNEZ, C.: "La sátira política durante el reinado de Carlos II", Cuadernos de Historia Moderna y Contemporánea, Madrid, 4 (1980), pp. 11-33. GonzÁlez MezQuita, M. L.: "El poder de las palabras. La "guerra de pluma" a comienzos del siglo XVIII", Fundación, V (2002), pp. 289-317.

13 Proceso criminal fulminado contra el Rmo.P.M. Fray Froylán Díaz, de la sagrada religión de predicadores, confesor del rey N.S.D. Carlos II y electo obispo de Avila. Que tuvo principio en el año pasado de 1698 y se concluyó en el de 1704 con Relación histórica del estado de esta Monarquía, y su gobierno. Madrid, 1787 y los Críticos documentos que sirven como de segunda parte al proceso criminal que se fulminó al M.R.P.M. Fr. Froylán Díaz Confesor que fue del Señor Rey Don Carlos II. Y constan de la célebre consulta que el Consejo de Castilla hizo al Señor Rey Don Felipe V, de su Real orden, sobre las determinaciones del Consejo de Inquisicion en esta causa y los procedimientos del Inquisidor general. De los tres votos singulares que dieron otros tantos Ministros del mismo Real Consejo y la consulta de este sobre ellos. Y de las notas que 
liza con detalle ${ }^{14}$. Los hechos han sido citados con frecuencia, pero las fuentes que utilizamos, si bien han sido aludidas, no han sido objeto de un análisis de su discurso. Habría que agregar que no todos los que hablan del Proceso lo leyeron, mientras que otros inventaron o tergiversaron los hechos y culparon a unos para salvar a otros. El duque de Maura realizó un estudio minucioso en su Vida y reinado de Carlos II y publicó un estudio sobre Supersticiones de los siglos XVI y XVII y hechizos de Carlos II concluyendo que de las fuentes se han transcripto los episodios escabrosos y que hubo dos víctimas de esta complicada trama: Díaz y Carlos II ${ }^{15}$. Pocos tratamientos del documento fueron realizados de manera desinteresada hasta los autores de producción reciente. Si bien muchos siguieron la idea de definir el conflicto como una simple intriga de palacio, se puede asegurar que trascendió esta categoría como lo demuestra Contreras ${ }^{16}$.

La Guerra de Sucesión Española fue un conflicto dinástico, civil e internacional en el que se opusieron no sólo dos candidatos, sino también dos formas de entender el gobierno. "El concepto de guerra santa o de cruzada, que intentó ser movilizada también desde el sector austracista, acabó imponiéndose en manos de los publicistas borbónicos"17. Los austracistas llegaron a considerar a Felipe V como un títere de Francia, que pasaba por ser la monarquía más impía de Europa y tenía la posibilidad

puso el M.R.P.M. Perez, Monge Basilio al escrito de D. Fernando de Frias, Fiscal del Santo Tribunal. Con privilegio Real y licencia necesaria. Madrid, 1788. La celebridad alcanzada por la versión manuscrita del Proceso criminal fue decisiva para su publicación. En 1787 apareció la primera edición y tuvo tanto éxito que Blas Román imprimió otra al año siguiente. Aquel mismo año José Doblado imprimió un Apéndice y Antonio Espinosa los Críticos documentos.

${ }^{14}$ Un informe detallado sobre aspectos historiográficos del Proceso criminal..., en CuETo RuIz, R.: Los hechizos de Carlos II y el proceso de fray Froilán Díaz, confesor real, Madrid, La Ballesta, 1966. Ya durante el XVIII circularon manuscritos y en 1725 el Marqués de San Felipe informaba al público en sus Comentarios. "parece que se culpa a la camarilla de los hechizos y lo hizo Froilán por docilidad y Froilán decidió usar los remedios de la iglesia". BACALlaR y SANna, V.: Comentarios a la guerra de España e historia de su rey Felipe V, el animoso, ed. y estudio preliminar de Carlos Seco Serrano, Madrid, Atlas, 1957,, p. 7

15 Aunque el texto es anónimo, todos los indicios parecen apuntar a Lorenzo Folch de Cardona y Pacheco, consejero de la Inquisición como su posible autor. En este texto se basaron MAuRA, Duque de: Vida y reinado de Carlos II, 2 vols., Madrid, Espasa-Calpe, 1954 y cueto Ruiz, op. cit. (nota 13, 1966). Vid. Rey Bueno, M.: El Hechizado. Medicina, Alquimia y superstición en la Corte de Carlos II (1661-1700), Madrid, Corona Borealis, 1998. Tuero Bertrand, F.: Carlos II y el proceso de sus hechizos, Gijón, Fundación Alvargonzález, 1998. El autor del Proceso es favorable a la Institución y muy crítico del Almirante, de Matilla y de la situación del reino debido a la violencia que ejercían sobre el rey que no podía tomar determinaciones. Maura utilizó cartas, autores coetáneos, archivos bávaros y austriacos sacadas a luz por el príncipe Adalberto de Baviera, BAVIERA, A. de y Maura y Gamazo, G.: Documentos inéditos referentes a las postrimerías de la Casa de Austria en España, Madrid, 1929, Tip. de la Rev. de Archivos, Bibliotecas y Museos, 2 vols, Maura y Gamazo, G.: Supersticiones de los siglos XVI y XVII y hechizos de Carlos II, Madrid, Saturnino Calleja, 1943.

16 Sin dudas hubo una intriga política, versión que fue reforzada por la publicación de Spain under Charles the Second or Extracts from the correspondence of the hon. Alexander Stanhope, British minister at Madrid 1690-1699, London, John Murray, 1840, pp 181 y ss. Incluye la correspondencia de Stanhope, enviado extraordinario inglés en Madrid, en especial la carta del 15 de julio de 1699 a su hijo Jaime: "Los doctores no sabiendo qué más hacer con el rey... dijeron que era hechizado y eso lo creyeron muchos en la corte aunque parezca ridiculo en Inglaterra. Es una maniobra para hacer pasar por bruja a la Berlips. Tampoco es la primera vez que este juego se realiza con éxito", vid. ConTreras, J.: Carlos II el Hechizado. Poder y melancolía en la corte del último Austria, Madrid, Temas de Hoy, 2003.

17 García Cárcel, R.: "Felipe V y la Inquisición", en Serrano, E. (ed.): Felipe V y su tiempo, Zaragoza, Institución Fernando el Católico (CSIC), 2004, II, $1^{\text {a }}$ pp. 597-612, 597. GARCía CÁrCel, R. y Moreno MarTíNEZ, D.: Inquisición. Historia crítica, Madrid, Temas de Hoy, 2000. Sobre la utilización del tema en campañas 
de adaptarse de acuerdo a las circunstancias con un racionalismo despótico de inspiración maquiavélica ${ }^{18}$

El análisis de estos temas intenta contribuir al mejor conocimiento de un período que fue calificado por Henry Kamen como la "edad oscura" de la moderna historiografía española. Este espacio comenzaría con el inicio del reinado del último de los Austrias y terminaría al finalizar el reinado del primero de los Borbones, en el que se sitúa el tránsito entre dos centurias "muy iguales y muy diferentes". ${ }^{19} \mathrm{Si}$ bien la producción de los últimos años permite matizar esta afirmación, todavía con motivo de la conmemoración de los trescientos años de la desaparición del último de los Austrias españoles, Ribot reflexionaba sobre la escasez de alusiones a esa conmemoración. Las razones podrían apuntar al "desconocimiento y el juicio peyorativo" que persisten sobre el reinado. Las investigaciones sobre el período -señala- a pesar de que no abundan, muestran una realidad bastante distinta, en la que conviven aspectos positivos y negativos ${ }^{20}$. La política bajo el reinado de Carlos II -como todo lo demás- tiene mala reputación. En general, el período se ha considerado -apunta Storrs- desordenado y revoltoso. Sin embargo, la política del reinado era a la vez más compleja y más seria ${ }^{21}$.

En el contexto de la renovación historiográfica, el interés despertado por la guerra y los procesos vinculados a ella en los últimos años -aunque muchos temas merecen aún investigaciones exhaustivas- se pone de manifiesto en las publicaciones de revistas especializadas, los resultados de los congresos sobre el tema ${ }^{22}$ y los trabajos, entre otros, de P. Fernández Albaladejo, R. García Cárcel, J. M. de Bernardo Ares, L. Ribot, C. Martínez Shaw, M. Alfonso Mola, V. León Sanz, F. Edelmayer, P. Molas, R. M. Alabrús, J. M. Delgado Barrado, A. Álvarez-Ossorio Alvariño. Y en el plano

de propaganda, vid. GonzÁlez CRUz, D.: Guerra entre príncipes católicos. El discurso del cambio dinástico en España y América (1700-1714), Madrid, Ministerio de Defensa, 2002.

18 Monod, op cit. (nota 4, 2001), p. 334.

19 Kamen, H.: La Guerra de Sucesión en España 1700-1715, Barcelona, Grijalbo, 1974.

20 Riвот, L.: “Carlos II: El centenario olvidado", Studia Histórica. Historia moderna, 20 (1999), pp. 19-43.

21 Storrs, Ch.: "La pervivencia de la Monarquía española bajo el reinado de Carlos II (1665-1700)", Manuscrits, 21 (2003), pp. 39-61, p. 54. Del mismo autor vid. historiografía del reinado y el concepto de "resiliencia": The Resilience of the Spanish Monarchy, 1665-1700, Oxford, Oxford University Press, 2006 (edición española, La resistencia de la Monarquía Hispánica (1665-1700), Madrid, Actas, 2013).

22 Entre otros, La Guerra de Sucesión en España y América, Actas X Jornadas Nacionales de Historia Militar (Sevilla, 13-17 de noviembre de 2000), Madrid, Deimos, 2001. Pereira iglesias, J. L. (coord.): Felipe $V$ de Borbón (1701-1746). Actas del Congreso de San Fernando (Cádiz), de 27 de noviembre a 1 de diciembre de 2000, Córdoba, Universidad de Córdoba, 2002. Guimerá Ravina, A. y Peralta Ruiz. V. (coords.): El equilibrio de los Imperios de Utrecht a Trafalgar, Madrid, Fundación Española de Historia Moderna, 2005. Álvarez-Ossorio Alvariño, A. (coord.): La pérdida de Europa. La Guerra de Sucesión por la Monarquía de España, Madrid, Fundación Carlos de Amberes, 2007. García GonzÁlez, F. (coord.): La Guerra de Sucesión en España y la batalla de Almansa. Europa en la encrucijada. Madrid, Sílex, 2009. Serrano, E.: (ed.): Congreso Internacional Felipe V y su tiempo, Zaragoza, Institución Fernando el Católico, 2004. LEón SANZ, V. (coord.): La Monarquía de España y los Tratados de Utrecht, Cuadernos de Historia Moderna, Anejo XIII (2013). Congreso Performances of Peace. Utrecht 1713-2013, organizado por el Departamento de Historia de Utrecht University y Dutch-Belgian Society of Eigtheenth-Century Studies. Utrecht, 24-26 abril, 2013. Congreso Internacional Los tratados de Utrecht: claroscuros de la paz. La resistencia de los catalanes. Museo Histórico de Cataluña y el Instituto Universitario de Historia Jaime Vicens Vives, Barcelona, Universidad Pompeu Fabra, 9-12 de abril de 2014. Torres Arce, M. y Truchuelo García, S. (eds.): Europa en torno a Utrecht, Santander, Universidad de Cantabria, 2014. 
de las relaciones internacionales: L. Bély, H. Kamen, CH. Storrs y L. y M. Frey. La obra del profesor J. Albareda ofrece una puesta al día del problema con el aporte de sus investigaciones personales y de un abordaje de la historiografía reciente. ${ }^{23}$

\section{CONTEXTOS Y ENTORNOS}

Si bien no eran nuevos los enfrentamientos entre el clero, la corona y la nunciatura ${ }^{24}$, nos centraremos en la finalidad particular que tenían, en el caso que analizamos, en función del regalismo ${ }^{25}$ que los inspira y de la resolución que le dará al conflicto Felipe V.

El avance del regalismo marcó un punto de inflexión en sus relaciones con los soberanos. No es que antes esta corriente de pensamiento no hubiese estado presente en España, pero ahora, gracias a la coyuntura bélica, muchas medidas que en otro momento podían ser consideradas abusivas, eran entendidas como necesarias para fortalecer el poder real ${ }^{26}$.

Este trabajo se propone analizar -en un contexto de especial conflictividad- no sólo el ya reconocido ascendiente que la opinión del clero tenía en la sociedad, sino los discursos y prácticas usadas desde el campo político y el religioso para comprobar, en un caso en especial, cómo se cruzaban y se convertían en instrumentos para manifestar las posiciones enfrentadas a propósito del conflicto sucesorio. Al mismo

23 Fernández Albaladejo, P. (ed.): Los Borbones. Dinastía y memoria de Nación en la España del siglo XVIII, Madrid, Marcial Pons, 2001. GArcía CÁRCEL, R.: Felipe V y los españoles: una visión periférica del problema de España, Barcelona, Plaza \& Janés, 2002. Molas, P., Cerro Nargánez, R. y Fargas Peñarrocha, M. A.: Bibliografía de Felipe V, Madrid, Sociedad Estatal de Conmemoraciones Culturales, 2004. KAMEN, H.: Felipe V, el rey que reinó dos veces, Madrid, 2000. Bernardo Ares, J. M. de.: La correspondencia entre Felipe V y Luis XIV: estudio histórico, informático y traductológico, Córdoba, Universidad de Córdoba, 2006. Riвot, L. (dir.): Carlos II: el rey y su entorno cortesano, Madrid, Centro de Estudios Europa Hispánica, 2009. Martínez Shaw, C. y Alfonso Mola, M.: Felipe V, Madrid, Arlanza, 2001. León Sanz, V.: La guerra de sucesión española a través de los consejos de estado y guerra del archiduque Carlos de Austria, Madrid, UCM, 1989. Edelmayer, F., León Sanz, V. y Ruiz Rodríguez, J. I. (eds.): Hispania - Austria III: Der Spanische Erbfolgekrieg - La Guerra de Sucesión española, Wien-München-Alcalá de Henares, Universidad de Alcalá de Henares, 2008. Alabrús, R. M.: Felip V i l'opinió dels catalans, Lleida, Pagés, 2001. Delgado Barrado, J. M.: Aquiles y Teseos: bosquejos del reformismo borbónico (1701-1759), Granada, Universidad de Granada, 2007. Álvarez-Ossorio Alvariño, A. (ed.): Famiglie, nazioni e Monarchia: il sistema europeo durante la guerra di Successione spagnola, Roma, Bulzoni, 2004. Y en el plano de las relaciones internacionales: BÉLY, L.: Les relations internationales en Europe (XVIIe.-XVIIIe. siècles), París, PUF, 1992. Albareda SALVAdó, J.: La Guerra de Sucesión de España (1700-1740), Barcelona, Crítica, 2010. GonzÁlez MezQuITA, (nota 1, 2007), González CRuz, D.: Propaganda e información en tiempos de Guerra. España y América (1700-1714), Madrid, Sílex, 2009. Siguen siendo de referencia obligada las obras de KAMEN, op. cit. (nota 18, 1974), y FREY, L. y Frey, M. (eds.): The Treaties of the War of the Spanish Succession: An Historical and Critical Dictionary, Westport, Connecticut, 1995.

24 Vatican, A.: "La nunciatura española bajo el reinado de Carlos II: Savo Millini (1675-1685)", Cuadernos de Historia Moderna, 26, (2001), pp. 131-147.

25 Sobre las relaciones Iglesia-Estado vid. entre otros: Negredo DEL CERro, F.: "Evolución de las relaciones Iglesia-Estado", en CoRTés PeÑA, A. L. (coord.): Historia del Cristianismo, Tomo III. Madrid, TrottaUniversidad de Granada. 2006.

26 Martín Marcos, D.: El Papado y la Guerra de Sucesión española, Madrid, Marcial Pons, 2011, p. 26. 
tiempo, se intentará destacar la intersección de las atribuciones jurisdiccionales entre el poder político y el religioso que tuvo derivaciones en clave regalista.

Los duelos reales o fingidos no eran extraños al mundo cortesano y uno, por demás relevante, tendría lugar en el ámbito de la corte madrileña a fines del siglo XVII poniendo en escena las intrigas de los bandos que defendían los intereses de los candidatos principales a la sucesión de Carlos $\mathrm{II}^{27}$. El Almirante de Castilla y sus seguidores defendían los intereses imperiales mientras que el Cardenal Portocarrero y el duque de Montalto, los del grupo opuesto. Montalto se resistía a la idea de traer al Archiduque a la corte y por eso había sido desterrado ${ }^{28}$. La segunda esposa de Carlos II, María Ana de Neoburgo, reunía en su entorno a varios personajes que resultaban beneficiados por su posición cercana a la reina. Los favores que recibían ${ }^{29}$, eran la causa principal del odio que los españoles pudieran sentir por los alemanes ${ }^{30}$.

La llegada en 1698 de Harcourt como nuevo embajador francés ${ }^{31}$, coincidió con los años en los que se iba a definir la cuestión sucesoria ${ }^{32}$. Es necesario, a pesar de la intención de simplificar el proceso en beneficio de su comprensión, prevenir sobre la complejidad de la realidad cortesana que impide las interpretaciones lineales sugiriendo "una visión más compleja de la cuestión sucesoria". Veremos -afirma Ribot- que hubo diversas alternativas, vaivenes, dudas e incertidumbres, que las cosas estuvieron lejos de ser tan claras como en muchas ocasiones se ha dicho"33. En carta de 4 de febrero de 1698, Luis XIV le pide a Harcourt que emplee todos los medios posibles para evitar que el rey tome alguna decisión favorable a la casa de Austria con respecto a su sucesión.

27 Haus-, Hof- und Staatsarchiv, Wien (HHStA Wien), W420, f. 377. GonzÁlez MezQuita, op. cit. (nota 22, 2007) p. 146. Carrasco Martínez, A.: El poder de la sangre. Los duques del Infantado. Madrid, Actas, 2010, pp. 106-107. KAmen, H.: La España de Carlos II, Barcelona, Crítica, 1981, p. 591 y ss. Kamen, op. cit. (nota 18, 1974), pp. 39-61. Hippeau, C. (ed.): Avenement des Bourbons au trone d'Espagne. Correspondance inédite du Marquis d'Harcourt publiée avec une introduction historique et des notes par C. Hippeau. Tome Premier, París, Didier et Cie., 1875, p. LV; García-Badell Arias, L. M.: "Los primeros pasos de Felipe V en España. Los deseos, los recelos y las primeras tensiones", Cuadernos de historia del derecho, 15 (2008), pp. 45-127.

28 El destierro fue breve porque el Almirante había constatado que provocaba malestar en los Grandes. Por esta razón decidió su regreso y al mismo tiempo invitó al Príncipe de Hesse para recomponer las filas de los austracistas. HHStA Wien, Handschrift W-344-559/1-6. CASTELLVI, F.: Narraciones históricas desde el año 1700 hasta el año 1725. Motivos que precedieron a las turbaciones de España, en particular a las de Cathaluña. Estado, resoluciones y fuerzas de las potencias interesadas en esta guerra, sitios de plazas, sorpresas, defensas, rendiciones, batallas, combates y reencuentros sucedidos en los Reinos de Castilla, Aragón, Valencia y sus confines, f. 44. (Hay edición reciente: Castellví, F. de: Narraciones históricas. Mundet, J. M. y Alsina, J. M. (eds.): 4 v. Madrid, Fundación Francisco Elías de Tejada, 1997).

29 LOuville, M. de.: Mémoires secrèts sur l'établissement de la Maison de Bourbon en Espagne, 2 vols., París, Maradan, 1818, p. 76, hace referencia a los fructíferos "negocios" de la cuestionada alemana.

30 Contreras, op. cit. (nota 15, 2003).

31 Álvarez López, A.: La fabricación de un imaginario. Los embajadores de Luis XIV y España, Madrid, 2008. Un análisis de periodo focalizando en la hispanofobia e hispanofilia a través del estudio de los embajadores franceses en Madrid.

32 GonzÁlez Mezquita, op. cit. (nota 22, 2007), pp. 155 y ss.

33 Riвот, L.: Orígenes políticos del testamento de Carlos II. La gestación del cambio dinástico en España, Discurso leído el día 17 de octubre de 2010 en su recepción pública en la Real Academia de la Historia. Madrid, 2010, p. 19. 
En 1698 se producirían además, dos cambios significativos en el entorno cortesano: el reemplazo del confesor del rey, P. Matilla ${ }^{34}$, por Fr. Froilán Díaz ${ }^{35}$ que había llegado al puesto por influencia de Portocarrero $^{36}$, y el alejamiento del Conde de Harrach padre, de su cargo como embajador imperial ${ }^{37}$.

En cuanto a las cuestiones de política europea, una “conspiración” internacional parecía armarse contra la Monarquía de España para traducirse luego en los Tratados de Reparto que habrían impulsado a Carlos II a dejar como heredero a un representante de la Casa de Borbón, en detrimento de la Casa de Austria, por considerar que la primera era la única que estaba en condiciones de asumir la defensa de la integridad de sus dominios ${ }^{38}$.

El Almirante trató de contener el progreso francés reconciliándose con el Conde de Oropesa, ofreciéndole el puesto de Primer Ministro con la Presidencia de Castilla y compartiendo el gobierno con él ${ }^{39}$. Era una buena decisión si hubiera sido tomada a tiempo ya que la crisis política que se estaba desencadenando tendría como consecuencia su alejamiento de la corte a raíz del motín de $1699^{40}$. El embajador informaba al Emperador que las negociaciones se complicaban ${ }^{41}$. Los partidarios de la alianza

34 Ibidem, f. 47.

35 López Arandia, op. cit. (nota 8, 2000), p. 117. "Un reinado marcado...por la formación de facciones y camarillas en el seno de la corte...las discrepancias entre órdenes religiosas especialmente notorias en la capilla real. A lo largo del reinado, los dominicos advierten cómo cada vez con más fuerza, su hegemonía al frente del confesionario real comienza a tambalearse".

36 Esto se consideró por parte de los enemigos de Portocarrero como una clara maniobra para desarticular el grupo del Almirante. Contra el gobierno del Cardenal Portocarrero, Memorial dirigido al rey Luis XIV de Francia el año 1700, Real Academia de la Historia (RAH), Madrid, Col. Salazar, K-26, f.155r.-177v. "El primer paso que dieron los coligados del Cardenal para practicar sus medidas fue arrojar del confesionario al Padre Matilla porque le sucediesse el padre Froilan que influido y engañado de ellos causo despues tan grandes y tan perjudiciales escandalos" (f. 158).

37 Sobre los confesores y su papel de consejeros se han realizado ensayos a partir de diferentes perspectivas, vid. López Arandia, M. A.: "El poder de la conciencia. Fray Gabriel de Chiusa, confesor de Mariana de Neoburgo", en Martínez Millán, J. y GonzÁlez Cuerva, R. (coords.): La Dinastía de los Austria. Las relaciones entre la Monarquía Católica y el Imperio. Madrid, Polifemo, 2011, vol. II. En este sentido, si bien de una época previa, es importante el trabajo de Negredo del Cerro, F.: Los predicadores de Felipe IV. Corte, intrigas y religión en la España del Siglo de Oro, Madrid, Actas, 2006. También FilipPINI, O.: "Permissiones divinas". Strategie di distinzione del confessore del sovrano e strategie di difesa dal confessore del sovrano nella monarquia del XVII secolo", Magina,13 (2009), pp. 103-112. Desos, C.: "Les confesseurs jésuites de Philippe V au début du XVIIIe siècle: agents français ou ministres du roi d'Espagne?, Magina,13 (2009), pp.159-174.

38 Los repartos se realizaron: El primero, en 1668 durante la Guerra de Devolución. En 1699, luego de la muerte de J. F. de Baviera, Francia e Inglaterra firmaron un segundo tratado que no se oficializó por oposición del emperador. Por último, se firmó el tratado de 1700 aprobado por Inglaterra y los Estados Generales. que llevó al rey a dejar como heredero al duque de Anjou con la condición de que mantuviera su monarquía intacta Riвот L. A.: "La España de Carlos II" en Historia de España de R. Menéndez Pidal, XXVIII. La Transición del siglo XVII al XVIII, Madrid, Espasa-Calpe, 1985, p. 241. LouvILLE, op. cit. (nota 30, 1818), p. 88, dice que fue en marzo de 1700. BotTineau, Y.: El arte cortesano en la España de Felipe V (1700-1746). Madrid, Fundación Universitaria Española, 1986.

39 Relazione di Spagna de Alvise Mocenigo dall anno 1698 al 1702. Relazioni degli Stati Europei lette al Senato dagli ambasciatori Veneti nel secolo desimosettimo raccolte et annotate de BAROZZI, N. e BERCHET, G., Serie I-Spagna Volume II, Venecia, 1860, p. 59. CASTEllví, op. cit. (nota 29, HHStA Wien), f. 47.

40 HHStA Wien. Verschinden Abschriften.

41 Maura, op. cit. (nota 40, 1954, T. II), p. 209. El informe de Harrach al Emperador de 28 de agosto de 1698 . 
con Francia aprovecharían otro episodio de la enfermedad ${ }^{42}$ del soberano para manifestarse ${ }^{43}$.

El rey firmó un testamento en el mes de noviembre de 1698 y declaró heredero al candidato de Baviera ${ }^{44}$, durante su minoría a su padre, y mientras éste se hacía cargo, al conde de Oropesa - gestor de este testamento- quien hizo todos los trámites con la sola compañía del Secretario del Despacho Universal, don Antonio de Ubilla ${ }^{45}$.

Cuando trascendió la firma del testamento, Harrach la comunicó a Viena provocando la lógica reacción del emperador. Luis XIV contaba en Madrid, a diferencia de Leopoldo I, con un habilidoso embajador, quien se encargaba de estrechar relaciones con el cardenal Portocarrero, el marqués de Mancera, el Inquisidor General, Rocaberti ${ }^{46}$ y el confesor del rey, Froilán Díaz, favorables a Francia y enemigos del conde de Oropesa.

En el marco de la trama tejida por intereses e intrigas de los diferentes involucrados en la sucesión española, la muerte inesperada el 6 febrero de 1699 del candidato bávaro, hizo que renacieron las esperanzas de los grupos enfrentados ${ }^{47}$.

Por su parte, el estado del rey propiciaba todo tipo de confusiones. La corte se había convertido en un lugar favorable para la circulación de rumores y el cruce de versiones sobre el tema sucesorio que generaban duda y desconcierto.

42 García-Escudero lópez, A., Arruza Echevarría, A., Padilla Nieva, J. y Puig Giró, R.: “Charles II: From spell to genitourinary pathology", Arch Esp. Urol., 62 (2009), 3, pp. 179-185. Los autores concluyen que se trata del caso de "un monarca pluripatológico que sólo se libraría de especulaciones (sobre su salud y condiciones físicas) si se efectuaran estudios cromosómicos y genéticos de sus restos presentes en el Monasterio de El Escorial", (p. 180). También vid. Rey Bueno, M.: "Estudio terapéutico de Carlos II el hechizado. Una corte de los milagros en el siglo XVII", Jano. Farmacia y Humanidades, 1 (abril 2001), pp. 16-22.

43 Castellví, op. cit. (nota 29, HHStA Wien), f. 63. Cuando Fernando de Harrach se despidió de los reyes para ir a Viena tenía la seguridad de que el bando del Emperador no tenía muchos adherentes. ( 9 de octubre de 1698). "Alguno reina sino la confusion el rencor, y la ira entre aquellos que debieran atender al remedio. La reyna y el Almirante lo mandan todo, Oropesa parece empieza a cansarse el cardenal y Monterrey se han unido y en algun modo son del partido de Francia en una palabra Señor del estado de esta corte y de su ministerio no se puede esperar sino la ruina de la monarchía".

44 Se establecía también la línea de sucesión en caso de que faltaran los designados, siguiendo lo establecido por las leyes de Castilla, Leopoldo y sus descendientes y, en tercer lugar, a la línea sucesoria de la infanta doña Catalina, hija de Felipe II y duquesa de Saboya. El testamento especificaba que la línea sucesoria preferente era la de la emperatriz Margarita, a la que seguía la de la emperatriz María, declarando excluidas de la herencia, por sus renuncias las líneas de las reinas Ana y María Teresa de Francia. En la decisión de renovar el testamento tuvo un peso considerable, la noticia de la firma del segundo tratado de Reparto entre Luis XIV y las potencias marítimas en la Haya el 11 de octubre. Se adjudicaba la Península Ibérica (con excepción de Guipúzcoa, Nápoles, Sicilia y los presidios de Toscana que recibía el Delfín) las Indias y los Países Bajos al Príncipe de Baviera, mientras el Archiduque recibiría el ducado de Milán, RiBot, op. cit. (nota 40, 1985), p. 150.

45 Antonio de Ubilla y Medina. Fue creado Marqués de Rivas en 1701 y perdió el favor real en 1706, por lo que tuvo que abandonar la Corte.

46 Ribot, op. cit. (nota 40, 1985), p. 142. Fray Tomás de Rocaberti arzobispo de Valencia, ocupaba el cargo, desde la muerte de Valladares a los 93 años en 1695, hasta su muerte el 13 de junio de 1699.

47 Hippeau, op. cit. (nota 28, 1875), p. 26, vol. II. Duque de Maine a Harcourt, 12 de febrero de 1699. 


\section{EL MOTÍN DE $1699^{48}$}

En el contexto de las reiteradas dolencias del rey y los arduos debates sobre la sucesión, comenzó a difundirse un rumor sobre supuestos hechizos ${ }^{49}$ que el Almirante, la reina y el conde de Oropesa habrían hecho al rey ${ }^{50}$. Froilán Díaz habría dado credibilidad a esta versión y habría aconsejado practicar exorcismos ${ }^{51}$. Portocarrero y Rocaberti apoyaron esta idea pensando que cualquier resultado perjudicaría a los supuestos culpables ante el pueblo. Se manifiesta una intención de utilizar los mecanismos adecuados para movilizar a los grupos populares y al mismo tiempo, la importancia que se asigna a su participación ${ }^{52}$. Maura hace un pormenorizado análisis del tema de los exorcismos y llama la atención sobre cómo se "adueñó del asunto la política" ${ }^{53}$. El resultado de estas prácticas no fue beneficioso para el rey que terminó sugestionado por los conjuros a los que fue sometido. Ante esta situación, Díaz "desistió" ${ }^{54}$, pero no lo hicieron Portocarrero y Rocaberti.

Manuel Arias, Portocarrero, Francisco Ronquillo y otros disconformes utilizaron el malestar popular por la carestía y el hambre para apartar del entorno real a sus principales opositores: el Almirante y Oropesa ${ }^{55}$ El marqués de Leganés contribuyó realizando una campaña de libelos y pasquines, en tanto que Ronquillo incentivó

48 Relación compendio de los sucessos de el dia veinte y ocho de abril de 1699. En el tumulto que se excito en la Corte y villa de Madrid. Biblioteca Nacional de España (BNE), Ms. 7178, f. 100-114.

49 Rey Bueno, op. cit. (nota 14, 1998); SÁnchez Belén, J. A.: "El gusto por lo sobrenatural en el reinado de Carlos II", Cuadernos de Historia Moderna y Contemporánea, 3 (1982), pp. 7-33. CuETo RuIz, R.: Los hechizos de Carlos II y el proceso de fray Froilán Díaz, confesor real, Madrid, La Ballesta, 1966. Rico Avelló y Rico, C.: "Carlos II. Sus tercianas, hechizos y dolencias”, Revista de Sanidad e Higiene Pública, 12 (1948). Garcia Barriuso, P.: "El milagrismo. Sor Luisa de la Ascensión, la monja de Carrión, Fray Froilán Díaz y el Inquisidor Mendoza”, en Pérez Villanueva, J. y Escandell Bonet, B. (dirs.): Historia de la Inquisición en España y América, Madrid, BAE, 2000, 3 vols, t. I, pp. 1089-1112.

50 CÁnovas del Castillo, A.: Bosquejo histórico de la Casa de Austria en España, Madrid, V. Suárez, 1911, p. 389. El autor no dudó en acusar al Almirante a quien considera "intrigante, altivo y audaz".

51 Louville, op. cit. (nota 30, 1818), p. 101. Algunas páginas más adelante, el autor precisa que el mismo Díaz fue acusado de practicar hechizos con el rey. Pero, en realidad su verdadera actividad no consistía en hechizar sino exorcizar. Era la reina quien aprovechaba la enfermedad del rey para su beneficio. El monarca estaba tan temeroso que llegó a creer que estaba en peligro de sufrir una metamorfosis.

52 EgIDO, T.: “El motín madrileño de 1699”, Investigaciones históricas, 2 (1980), pp. 255-294. Según se sostiene en este artículo, un motín urbano de corte que parecía poco importante, se convirtió en un hecho político al comprometer en sus consecuencias a facciones de la corte. RiBot, op. cit. (nota 40, 1985), ha opinado que las consecuencias del motín pueden mirarse desde otra óptica si se considera que no es fácil identificar esas facciones, porque se trataba de grupos que apoyaban las distintas candidaturas a la sucesión española, cuya identidad es, en algunas oportunidades, cambiante. Los efectos del motín no serían tan claros en beneficio de unos y perjuicio de otros. Vid. Nieto SÁnchez, J. A. y González Pañero, J. A: "El conflicto social en el Madrid del siglo XVII", en GuIllamón, F., J. y Ruiz IbáÑEZ, J. J.: Lo conflictivo y lo consensual en Castilla. Sociedad y poder político, 1521-1715, Murcia, 2001, pp. 377-400. Apud. Riвot, L.: "La sucesión de Carlos II. Diplomacia y lucha política a finales del siglo XVII”, en García Fernández, M. y Sobaler Seco, M. A. (coords.): Estudios en homenaje al profesor Teófanes Egido, Valladolid, Junta de Castilla y León, 2004, vol. I, pp. 63-99.

53 Maura, op. cit. (nota 40, 1954, T. II), p. 299.

54 Defensa de Froilán Díaz confesor de Carlos II y del Consejo de la Inquisición. Los eclesiásticos seculares y regulares de la Corte y los vecinos escriben un papel en defensa de su "inocencia y fidelidad". Bibliothèque Nationale Paris (BNP), Ms. 7157. f. 234. También, Ms. 7157. f. 238. Breve resumen de la controversia entre el Inquisidor general y el Consejo de la Inquisición a que ha dado motivo la causa del Padre Froilán Díaz.

55 RIBOT, op. cit. (nota 54, 2004), p. 75. 
el malestar en el pueblo respecto a las malas cosechas, en especial la de 1698 y el consecuente aumento del precio del trigo, la harina y el aceite, culpando a Oropesa ${ }^{56}$ aunque también se incluían los nombres de la reina y su confesor, Gabriel Chiusa ${ }^{57}$.

Este conjunto de variables, explica cómo una situación, que en otras circunstancias podría superarse sin dificultades, desencadenó una reacción generalizada en Madrid el 28 de abril de 1699. Llegaron los amotinados a la plaza del Palacio Real ${ }^{58}$ atemorizando al monarca. "El día fue el primero semejante que a tenido la Corte Española" 59 . El rey y la reina se retiraron y la guardia tomó las armas para defender las puertas ${ }^{60}$.

Los amotinados saquearon e incendiaron la casa del conde de Oropesa y la familia del conde huyó. En la casa del Almirante la situación fue peor debido a la resistencia armada que ofrecieron los criados ${ }^{61}$. El Motín contra Oropesa o "Motín de los Gatos" no fue sólo un estallido popular típico de una crisis de subsistencias, expresaba también un conflicto político en el que un bando cortesano era reemplazado por otro. La identificación de ambos bandos con los defensores de opciones sucesorias es un tema aceptado por algunos autores. Ribot plantea que es necesario establecer precisiones ya que algunos de los vencedores no se identificaban con la opción francesa. Queda fuera de los alcances de este artículo el debate sobre la existencia de bandos consolidados en la corte de Madrid y su genealogía de la que ya nos hemos ocupado con anterioridad ${ }^{62}$.

\section{DESTIERRO DE OROPESA Y DEL ALMIRANTE DE LA CORTE}

Portocarrero fue el autor del decreto por el cual el rey desterró a Oropesa y al Almirante, que seguirían en esta condición hasta la muerte del rey ${ }^{63}$. Cambiaba la camarilla que ejercía el poder. "En esta forma quedaron sin rival las pretensiones del Cardenal y quedo el Rey expuesto a todas las indecencias que después se egecutaron con su sagrada persona" ${ }^{64}$. Un ejemplo del poder del Cardenal y del descenso del Almirante así como del cruce de jurisdicciones e intereses, puede considerarse el caso del Conde de Cifuentes. Como derivación de la conflictiva relación entre el Almirante y Cifuentes a partir del desafío que había tenido lugar en 1697, se produjeron una

\footnotetext{
56 MAURA, (nota 40, 1954, T. II), p. 257 El autor lo llama Motín de Oropesa y basa su relato en el testimonio contemporáneo del médico real, Dr. Geleen en carta al Elector Palatino el 8 de mayo de 1699.

57 Se trata de fray Gabriel Pontiferrer nacido en Chiusa, Tirol, en 1653

58 CÁNOvas del CASTILlo, op. cit. (nota 52, 1911), p. 403.

59 RAH, Col. Salazar, K-26, (nota 38), f. 161v.

60 GonzÁlez MezQuita, op. cit. (nota 22, 2007), pp. 171

61 Relazione di Spagna de Alvise Mocenigo dall anno 1698 al 1702, op.cit. (nota 39), p. 496.

62 Contreras, op. cit. ( (nota 15, 2003), p. 303. Sobre la formación de bandos o partidos, además de la nota 54 de este trabajo, vid. en especial, Ribot, op. cit. (nota 34, 2010), GonZÁlez MezQuita, op. cit. (nota 22, 2007) y Maquart, M. F.: Le Réseau français à la Cour de Charles II d'Espagne: jeux diplomatiques de fin de règne: 1696-1700, Villeneuve-d'Asq, Presses Universitaires du Septentrion, 2002.

63 RAH, Col. Salazar, K- 24, f. 42-68. Hippeau, op. cit. (nota 28, 1875), p. 83. El embajador al rey. Carta del 18 de mayo de 1699 p. 80 y 26 de mayo de 1699. KAMEN, op. cit. (nota 26, 1981), p. 609. El vacío de poder condujo a apresuradas negociaciones entre los bandos. La víctima principal fue el Almirante que fue desterrado de la Corte.

64 RAH, Col Salazar, K-26, op. cit. (nota 38), f. 162r.
} 
serie de incidentes que marcaron un cambio en la tendencia ascendente en la vida del primero. Habiendo vencido los plazos de la causa por estos hechos, se dieron por terminadas las actuaciones legales. Portocarrero propuso, a pedido de Cifuentes, que se quemaran los autos, a pesar de la resistencia ofrecida por el nuevo Inquisidor General, Baltasar de Mendoza (1699-1705), obispo de Segovia, y de la negativa del dictamen del Consejo de Castilla, cuyos integrantes, a pesar de la presión de su Presidente, don Manuel Arias, se opusieron al incendio de los papeles, cuyo destino es discutido.

En su testamento de 2 de octubre de 1700 el rey eligió como sucesor a Felipe de Borbón, duque de Anjou, poniendo en primer lugar los derechos de su abuela María Teresa. Derogó las leyes que se opusieran a su voluntad y puso como condición que las coronas de Francia y España no se unieran bajo ninguna circunstancia ${ }^{65}$. Luego de la firma del testamento, el 10 de octubre lo ratificó en un codicilo y se prohibió la entrada a todos los que eran sospechosos de inducir al rey a favor del candidato austríaco, en especial el conde de Harrach, embajador imperial. La muerte del rey se produjo el $1^{\circ}$ de noviembre del mismo año ${ }^{66}$.

\section{ANÁLISIS DEL PROCESO}

No pretendemos aquí dar cuenta de la veracidad o exactitud de los datos vertidos en el documento, trabajo ya realizado por otros autores ${ }^{67}$. Sólo trataremos de señalar la existencia de un discurso con una intencionalidad que va más allá de un relato con valoración hagiográfica de unos o denigración de otros. El análisis que realizamos nos ha permitido comprobar el cruce de jurisdicciones que se pone de manifiesto en el discurso de este Proceso y las prácticas que lo acompañaron como manifestación de los intereses cruzados que se ponen en evidencia. Como adelantamos, el documento se refiere a la confusa situación que genera la enfermedad del rey y a los arbitrios aplicados para su curación

El Consejo de Castilla previene a los posibles lectores sobre eventuales deformaciones de la información vertida en el texto en los siguientes términos:

Nota que manda poner al principio de esta obra el Supremo Consejo de Castilla Para evitar qualquiera mala inteligencia que se quiera dar á esta obra, ha acordado el Consejo, que advierta al Público por medio de esta Nota, que debe leerse con aquella precaución necesaria para no dar mas opinión, ni crédito, que el que corresponde a las especies y noticias que contiene ${ }^{68}$.

Las quejas generadas por las acciones de la camarilla alemana de Mariana de Neoburgo constituyen el centro de una trama que ofrece al Cardenal Portocarrero y sus seguidores una oportunidad para asumir una posición de poder en la Corte. Los inte-

65 García-Gallo, A.: El origen y la evolución del derecho, Madrid, 1984, vol. I, p. 775.

66 Carta del Cardenal Portocarrero al rey de Francia dandole parte de estar firmado el testamento a favor del Serenisimo Duque de Anjou, HHStA Wien. W 428, s/f.

$67 \mathrm{Vid}$. notas 14 y 15.

68 Proceso criminal, p. 3. 
grantes de la que sería nueva camarilla, diseñaron una estrategia que tendría consecuencias encadenadas. Entre los mecanismos a utilizar, optaron en primera instancia por el cambio del confesor real, Matilla, designando en su lugar a Fr. Froilán Díaz, protagonista central del Proceso $^{69}$. Se planteaba la necesidad de desplazarlo porque era "tirano de la real conciencia... y fomenta su perdición, ocultándole por bueno lo mas perverso". ${ }^{70}$ Los confesores reales disponían de mucha influencia y poder con un campo de intervención en el gobierno de beneficiosa indefinición ${ }^{71}$. Se podían considerar verdaderos ministros informales situados en la encrucijada entre religión y política $^{72}$. Pero también se podrían ver como consejeros del rey en su función de guías espirituales, ya que los dictámenes morales sobre los actos del soberano "suponían un consejo, quizá indirecto, sobre el modo en que éste debía gobernar a sus súbditos y conducir la política internacional"'73.

El nuevo confesor llegaba a sugerencia de Portocarrero y entró "repartiendo al mismo tiempo cargos a unos y destierros a otros, según los efectos, y pasiones de cada uno, y nadie se persuadía a que no habría otras muchas novedades..."74. Díaz se aseguraba dos lugares privilegiados como consejero de la Inquisición y confesor real "con que desde ahora se empiezan a tirar las líneas para uno de los casos más peregrinos que se han visto y es el asunto único de este informe y verídica relación"75.

El Almirante conocía todos estos movimientos por su condición de presunto "valido" "76 y, si bien discutió con sus seguidores algunas propuestas, no tomó ninguna decisión ${ }^{77}$. Los resultados de la maniobra de Portocarrero tendrían mucho impacto "porque el tiro que ha disparado el Cardenal sobre todos, es tan cruel que á haberle experimentado semejante aquellos grandes Héroes Mazarini y Richielieu, hubieran, sin duda, zozobrado en sus privanzas".

\footnotetext{
69 López Arandia, op. cit. (nota 8, 2009).

70 Proceso criminal, p. 29
}

71 Poutrin, I.: "Los confesores de los reyes de España: Carrera y función (siglos XVI y XVII)", CorTÉS Peña, A. L., Beltrán, J. L. y Serrano Martín, E. (coords.): Religión y poder en la Edad Moderna. Granada, Universidad de Granada, 2005, pp, 67-81 (69).

72 Los confesores reales, jesuitas con los Borbones, influirán sobre todo, en asuntos de administración de justicia, de universidades y de Inquisición. En el período que nos ocupa G. Daubenton (1700-1705). GómEZ Rivero, R.: "Consejeros de la Suprema de Felipe V”, Revista de la Inquisición 4 (1995), pp. 133-175 (137).

73 Martínez Peñas, L.: El confesor del rey en el Antiguo Régimen, Madrid, Editorial Complutense, 2007, p. 944.

74 Proceso criminal, p. 39.

75 Ibidem, p. 66.

76 Ibidem. Se descartó al P. Matilla "o por considerarle sospechoso como interesado, o porque sabiendo estaba caido, le miro como a trasto inútil... Concurrieron el P. Gabriel Chuza Capuchino, confesor de la reina, don Isidro Camargo, el conde de Adanero (Secretario del Despacho), el conde Clavijo, el Marqués de Zelada, el P. Casnedi, jesuita, Fr. Antonio Folch de Cardona, Comisario General de San Francisco y otros".

77 Proceso criminal, p. 50. El más inteligente fue Antonio Folch de Cardona (amigo del Almirante desde los tiempos en que había integrado la Guardia de la Chamberga) - dice el autor del Proceso (se supone que es Lorenzo Folch de Cardona) y para conocerlo mejor traza una biografía del mismo - "Este pues, que estaba muy versado en representar diferentes papeles, como si fuera único en cada profesión, pues en los Claustros le tenían por extático; en las funciones literarias por Maestro; en las Ciudades y Corte por refinado político, como también perfecto cortesano". 
Pero el nuevo confesor tenía muchos enemigos y para manejarse en la corte le hacían falta otros conocimientos y prácticas diferentes de aquellas "que enseñan el Coro y la Cátedra, bien desemejantes de aquellas que practican los políticos Estadistas"78.

La enfermedad del rey era un problema acuciante y circulaban rumores sobre posibles maleficios que la ocasionaban ${ }^{79}$. Por tratarse de un tema que no era nuevo, a comienzos de 1698, el rey encargó al Inquisidor General, Juan Tomás de Rocaberti ${ }^{80}$, que se ocupara de investigar qué había de cierto en estas versiones. El Inquisidor informó sobre el tema en su Consejo, el cual trató de tomar distancia y las debidas prevenciones

Aquel Senado tan santo, como sabio y político, le respondió era muy dificultoso, se pudiese entrar en semejante laberinto, sin el hilo de alguna noticia, indicio o sospecha en persona determinada... lo que únicamente se podía arbitrar era estar con gran vigilancia y precaución siempre a la vista de lo que se oyese o se viese o si el Rey confiase a S. E. algún hecho o sugeto en quien sospechase y la razón que para ello tuviese, entonces habría materiales sobre que recayesen discurso y operación, pero hasta tanto, solo debían aplicarse a encomendar a Dios muy de veras al rey en sus operaciones y sacrificios $^{81}$.

Rocaberti no se conformó con el dictamen del Consejo y en abril del mismo año, le encargó a Díaz que se ocupara de la cuestión ${ }^{82}$. Díaz recurrió a Fr. Antonio Álvarez de Argüelles, que era confesor y vicario de un convento de dominicas recoletas en la villa de Cangas y hablaba con el demonio porque conjuraba dos o tres religiosas del convento estaban "espirituadas". Rocaberti quiso involucrar al obispo de Oviedo, Fr. Tomás Reluz, dominico que no aceptó el encargo y escribió:

Siempre he estado persuadido a que en el rey no hay mas hechizo que un descaecimiento de corazón y una entrega excesiva de voluntad a la Reyna (como se experimenta en otras personas) y en el ínterin, que el Confesor no trabaje, no se hallará otro remedio $^{83}$.

El confesor se ocupaba no sólo de los hechizos sino de la trama política que se desarrollaba en torno a la figura real. Como se ha hecho notar, si bien no hay un cambio en la labor del confesor del rey en el reinado de Carlos II, "sí es cierto que el

\footnotetext{
78 Proceso criminal, p. 68

79 Ibidem, p. 75. Algunos años antes, siendo Inquisidor General, Diego Sarmiento Valladares, se había tratado el tema en el Consejo de la Inquisición pero, por defecto de las pruebas o porque se creyó que no había méritos suficientes para la investigación "se hubo de sobreseer en el asunto".

80 Dominico, hijo de los Condes de Peralada, llego a ser General de toda la Orden y Arzobispo de Valencia. El autor del Proceso criminal lo define como "sencillo y docto pero ingenuo y algo pagado de sus juicios".

81 Ibidem, p. 76.

82 Barrios Pintado, F.: "Las competencias normativas del Inquisidor General en la normativa regia de los siglos XVI y XVII. Una aproximación al tema”, Revista de la Inquisición, 1 (1991), pp. 121-140. Sobre las competencias del Inquisidor General, vid. (129 y ss.)

83 Proceso criminal, p. 83.
} 
confesionario regio se nos presenta en estos años claramente sometido a los vaivenes políticos que se viven en la corte" ${ }^{84}$.

El 18 de junio 1698 el propio Rocaberti escribió a Argüelles y le pidió que averiguara si los reyes tenían algún maleficio. El asturiano dijo que el demonio juró que el rey había sido hechizado a los catorce años con una bebida que le habían administrado en un chocolate ( 3 de abril de 1675). La bebida se la había dado una mujer por orden de la reina Ana de Austria, para poder reinar sin obstáculos.

Pero ¿se habían repetido los hechizos después de 1675? Argüelles aseguró que hubo otra oportunidad y "que el hechizo de 24 de septiembre del año 94 se lo dio al Rey uno que tiene gana y deseo de que venga a España el Archiduque... que en lo exterior le hace muchas fiestas y cariños al Rey pero en lo interior le tiene, como el ultimo Apóstol". Jura que no puede decir su nombre, "pero por sus señas lo pueden vuestras mercedes conocer". Esta se supuso una acusación velada al Almirante. Pero, en noviembre de 1698 dice que los demonios no quieren seguir acusando y niegan lo que habían afirmado antes ${ }^{85}$.

Hasta junio de 1699 siguen cartas con esta discusión. En esa fecha murió Rocaberti y terminó la correspondencia. El caso se complicó pues Leopoldo I envió al capuchino Mauro Tenda para ayudar al rey. El monarca pidió a Tenda que exorcisara a una mujer que había entrado en el palacio y terminó involucrando a la reina y al Almirante entre otros. La reina se enfureció con Froilán por vincularla con los maleficios y se propuso que el Santo Oficio lo declarara reo de $\mathrm{fe}^{86}$ pero los consejeros respondieron que no se animaban a decidir en la cuestión.

El rey designó nuevo Inquisidor General al Cardenal Córdoba ${ }^{87}$ quien, declaró que "combinando los cabos sueltos de las proposiciones que el demonio había proferido por medio de las energúmenas, le parecía no podía dexar de estar complicado en esta maldad el Almirante" a quien proponía apresar en Granada ${ }^{88}$. Pero Lorenzo Folch de Cardona le manifestó que para arrestar al Almirante, era necesaria semiplena probanza de que hubiera delinquido en una materia que correspondiera a la jurisdicción inquisitorial, y esto estaba lejos de haber sucedido. Por otra parte, las pruebas no pasaban de ser declaraciones inconsistentes proferidas por el "padre de la mentira para temer que fuese todo una falsedad que solo sirviese de confundir lo que se pretendía aclarar". La iniciativa de Córdoba no pudo seguir adelante porque murió a la brevedad.

84 Martínez Peñas, op. cit. (nota 76, 2007), p. 474.

85 Proceso criminal, p. 101.

86 Contreras, J.: "Guerra entre Inquisidores. Los antecedentes del proceso de Don Melchor de Macanaz", en Muñoz Machado, S. (ed.): Los grandes procesos de la Historia de España, Barcelona, Crítica, 2002, p. 297

87 Proceso criminal, p. 12. "Don Alonso de Aguilar, Cardenal Cordoba, era hijo legitimo de los Marqueses de Priego, antes de venirle el capelo cardenalicio se llamaba y firmaba de Aguilar, sin embargo de ser su principal Varonía Fernández de Córdoba, por la costumbre que esta antiquísima casa observaba de que el hijo segundo se llevase el apellido de Aguilar en memoria de aquel insigne y valeroso héroe, que murió peleando contra los moros de las Alpujarras en tiempo de los Reyes Católicos". La reina no consiguió como deseaba el cargo de Inquisidor General para Antonio Folch de Cardona, más tarde arzobispo de Valencia.

88 Proceso criminal, p. 135. 
En esta instancia, la reina propuso como Inquisidor General a Baltasar de Mendoza (partidario de la sucesión austríaca) ${ }^{89}$. El primer castigado resultó Tenda, que fue desterrado. Llamaron a declarar a Díaz pero se negó alegando que todo lo había hecho por orden del rey.

En el Consejo de Inquisición la opinión era que no se debía seguir con este tema pero, apareció un dominico conventual de nuestra Señora de Atocha (fray Cristóbal Donaire) y en nombre y con poder de su provincia, presentó una delación contra Froilán, que contenía tres partes: La primera, se basaba en unos autos realizados por un religioso de su orden -por orden de fray Nicolás Torres-Padmota/Palmota/Palmosaque había ido al convento de Cangas y conocía lo que el confesor del convento había hecho en los exorcismos con las energúmenas en 1698 y 1699 y que había encontrado cartas firmadas por Cambero de Figueroa, Secretario de Cámara de Rocaberti, en las que por orden del propio Rocaberti le pedían a Argüelles que hiciera exorcismos para obtener declaraciones del demonio. También se hallaron cartas de Froilán en las que le decía que no perdiera tiempo en los pedidos del Inquisidor General. La segunda parte, se refiere a hechos de Froilán en Alcalá y otros lugares y a su hipocresía. La tercera parte refiere acontecimientos ocurridos en Valladolid.

Díaz volvió a declarar, afirmando en esta oportunidad, que lo que se hizo fue por orden de Rocaberti. Mendoza puso en conocimiento del rey que Froilán estaba procesado pero que no podrían proceder por ser confesor real. Por esta razón fue reemplazado por Nicolás Torres. Froilán huyó a Roma pero, el embajador, duque de Uceda, lo hizo regresar a Madrid. El Inquisidor lo acusó de violar las regalías de España que penaban el recurso a Roma de los tribunales de la Inquisición ${ }^{90}$.

El tema se volvió a tratar y se designaron calificadores que concluyeron el 23 de junio de 1700 que no podía ser reo de fe. Por estas razones el Consejo de la Inquisisción votó que se suspendiera la causa, pero el Inquisidor General dispuso que siguiera y que fuese preso. El Consejo no respondió por considerar que el voto de uno sólo no tenía efecto frente al del cuerpo, pero el 8 de junio de 1700 un auto de prisión contra Díaz requería la firma de los consejeros quienes alegaron que no podían hacerlo por ser un tema que no habían resuelto ni votado. Ante esta decisión el Inquisidor mandó prender a tres consejeros: Antonio Zambrana, Juan Bautista de Arzeamendi, Juan Miguélez y al Inquisidor de corte, el Secretario de la Suprema, Domingo Cantolla:

Todos aquellos que no estaban teñidos de la venganza de la reina, del odio de los Frayles, ó de la pasión de los parientes y domésticos del señor Inquisidor General,

89 Barrio Gozalo, M.: "La oposición a los Borbones españoles y el exilio de eclesiásticos. Don Baltasar de Mendoza y Sandoval, obispo de Segovia e Inquisidor General", Anthologica Annua, 43 (1996), pp. 590591. Apud. SoLís, J.: "La organización del Santo Oficio y el nombramiento de Inquisidor General por el Archiduque Carlos (1709-1715)", Hispania, LXV/2, 220, (2005), pp. 515-542 (522).

90 Con estos argumentos convence al rey para que vuelva a España. Lo llevan preso a Murcia donde se designaron nueve Calificadores que declaran lo mismo: "no haber lugar a la prision del reo". Lo liberan pero desde Madrid lo van a buscar y lo encierran el Colegio de Santo Tomás donde permaneció tres años. Sobre la Inquisición y la Guerra de Sucesión, vid. Domínguez Salgado, M. P.: "Inquisición y Guerra de Sucesión (1700-1714)", Espacio, Tiempo y Forma, 8 (1995), pp. 175-189 y EGIDO, T.: "La Inquisición de una España en guerra" en Pérez Villanueva, J. y Escandell Bonet, B. (dirs.): Historia de la Inquisición en España y América, Madrid, 1989, vol. I, pp. 1227-1230. 
censuraban estas prisiones por atropelladas é injustas, al paso que los referidos contrarios voceaban que Froylán eran herege, los Inquisidores de la Suprema inobedientes á su Gefe y también cismáticos, pues defendían á quien había practicado una doctrina herética y que el Secretario era un falsario ${ }^{91}$.

Los defensores del Inquisidor General, opinaban que su autoridad era absoluta en todas las cuestiones de justicia, que los Consejeros no tenían voto decisivo sino sólo consultivo, y que tenían la obligación de suscribir sus resoluciones. Por su parte, los consejeros que criticaban el autoritarismo del Inquisidor General, y entendían que quería someter a su voluntad al resto del Consejo, aseguraban que al solicitar su firma se buscaba justificar la prisión de Díaz, hacer pasar por justa la decisión tomada con los tres consejeros y el secretario y por último definir el poder del Inquisidor como absoluto. A pesar de estos argumentos, jubilaron a los tres consejeros y desterraron al secretario por cuatro años. Los rumores contra el Inquisidor provocaron que el Consejo de Castilla hiciera consulta al rey sobre la escandalosa situación ${ }^{92}$.

Con la llegada del nuevo rey, Felipe V, tanto los dominicos, que habían pedido ayuda a Roma, como el Nuncio pontificio monseñor Acquaviva, quisieron beneficiarse con estos hechos ${ }^{93}$. El conflicto jurisdiccional entre Madrid y Roma estaba planteado ${ }^{94}$. La Santa Sede apoyó la interpretación del Inquisidor General, aseguró que podía intervenir en el proceso inquisitorial contra Díaz y rechazó la suspensión que había sufrido Mendoza (1702). También se argumentó que el Consejo de Inquisición no tenía facultades sobre la jurisdicción apostólica delegada en el Inquisidor General. Los consejeros, por su parte, insistían en que tal doctrina iba en contra de las regalías de la Corona de España y vulneraba el privilegio de inapelabilidad de la Inquisición Española. En el debate, el nuncio mantuvo que por ser una causa de fe la decisión correspondía a Roma mientras que Lorenzo Folch defendió la posición regalista.

La política eclesiástica ocupó un lugar central dentro del proyecto de imposición de supremacía de la autoridad real en todos los ámbitos de la Monarquía de España por parte de los Borbones. Sus objetivos se orientaron al fortalecimiento de la autoridad frente a las injerencias del Papado. Por otra parte, también se debe considerar -señala López Vela- el austracismo del Inquisidor General y los partidarios de esta posición dentro de la institución que suponían amenazada su posición por Felipe $\mathrm{V}$, si bien no se podría argumentar sólo en esta dirección si se toman en cuenta los conflictos que tuvieron lugar durante el reinado de Carlos II y los argumentos de T. Egido sobre el regalismo del Archiduque en Cataluña ${ }^{95}$ :

91 Proceso criminal, p. 171.

92 Ibidem, p. 183.

93 BNE, Ms. 1.784 Consulta de este Consejo de la Inquisición a Felipe V sobre una carta que recibió el Inquisidor general del Cardenal Pauluchi, secretario de Estado de S. S. para que el Consejo no entendiese en la causa del P. Froilán, cit. por Torres Arce, M.: Inquisición, regalismo y reformismo borbónico. El tribunal de la Inquisición de Logroño a finales del Antiguo Régimen, Santander, Universidad de Cantabria, 2006, p. 29.

94 Martin Gaite, C.: Macanaz, otro paciente de la Inquisición, Madrid, Taurus, 1975 p. 94.

95 López Vela, R.: "La Inquisición a la llegada de Felipe V. El proyecto de cambio en su organización y bases sociales", Revista Internacional de Sociología, 46, 1, 1988, pp. 63-123, p. 72. EgIDo, T.: "Regalismo y relaciones Iglesia-Estado en el siglo XVIII" en Historia de la Iglesia en España, t. IV, Madrid, BAC, 1979. 
En concreto, la política regia en el setecientos respecto a la Inquisición se centró prácticamente en los mismos terrenos y objetivos que se tuvieron con otras instituciones eclesiásticas del reino... Para ello se pugnaría por separar al Tribunal de su dependencia de Roma arrebatándole al Inquisidor General la jurisdicción que manejaba y sus atribuciones en materia de gracia y gobierno a favor del Rey, el Consejo Real y el propio Consejo de Inquisición ${ }^{96}$

Las controversias jurisdiccionales se sumaban a la que se había planteado sobre si el Consejo de Inquisición tenía o no voto decisivo, si las Bulas delegaban toda la jurisdicción apostólica en el Inquisidor General a título personal o con su Consejo. Estos enfrentamientos con el poder civil no son una novedad propia de la dinastía si bien fueron utilizados con especial énfasis para la afirmación de su autoridad. En el siglo XVII la Inquisición había sufrido una ofensiva por parte de la autoridad regia con los mismos objetivos finales en los que se centraron los primeros Borbones, esto es, su conversión en una regalía de la Corona ${ }^{97}$.

La actitud del Nuncio aunque parecía proteger al Inquisidor General, en realidad, quería sacar partido del conflicto para extender su jurisdicción y la de la Santa Sede en contra de la independencia de la Inquisición de España, por eso

excitó de nuevo otras especies, que fueron representar que esta controversia, era eclesiástica en el todo y en su parte ¿cómo podría poner paz y concordarlos ningún príncipe secular por soberano que fuese y mucho menos los podrían componer sus tribunales siendo también seculares? Luego a sus santidad solamente tocaba decidir esta contienda ${ }^{98}$.

Lorenzo Folch de Cardona respondió al Nuncio con dureza en un impreso afirmando que no se estaba discutiendo un principio de fe tal como se venía sosteniendo ${ }^{99}$. Ante la supuesta ofensa que se habría infligido al representante del Papa, Cardona contestó que esperaba las razones de su ofensa por escrito y agregó que él también daría otra respuesta y "la esparcería por toda la corte y que lo mismo haría en la de Roma...". Esta amenaza de una posible "guerra de pluma" parece haber silenciado al Nuncio. La importancia de la formación de redes textuales polémicas y la conquista

96 Torres Arce, op. cit. (nota 96, 2006), pp. 27-29. Vid. en esta obra, una actualizada bibliografía y debates sobre la institución inquisitorial. También en un plano más general CoRTÉs PeÑA, A. L. y LóPEZ-GuADALuPE MuÑoz, M. L. (eds.): La Iglesia española en la Edad Moderna. Balance historiográfico y perspectivas, Madrid, Abada, 2007.

97 López Vela, R.: "Estructura y funcionamiento de la burocracia inquisitorial (1643-1667)" en Inquisición española. Nuevas aproximaciones. Madrid, 1987 pp. 159-231. Apud. Torres ArCE, op. cit. (nota 96, 2006), p. 27.

98 Proceso criminal, p. 191.

99 Ibidem, "Afirma el nuncio que las personas que litigan son en mayoría eclesiásticos... porque de un lado esta el Inquisidor y de otro el Consejo de la Inquisición... Y que siendo unos y otros instituidos para el conocimiento de las causas de fe, estaban investidos de la jurisdicción Apostólica por eso solo el Papa podía poner paz... A esto se responde al Nuncio que es cierto pero que se omiten las circunstancias que hacen ilegitimas las consecuencias que saca el Nuncio, porque en el Inquisidor Gral. hay jurisdicción apostólica que recibe de la Santa Sede, pero como presidente de un Consejo del Rey como es el de Inquisición, no puede eximirse de ser vasallo de S.M. y lo mismo para los consejeros de Inquisición... Entonces ¿por que no podrá el rey concordar y poner en paz a un Presidente de Consejo suyo que litiga con el mismo Consejo que también es de S. M.?” 
de la opinión se pone, una vez más de manifiesto, tanto como la necesidad de su control ${ }^{100}$.

La consideración del Rey como "Protector, Patrono y Dotador de la Inquisición" que encabeza el Decreto Real de 1703 supone una declaración de las regalías de la Monarquía ${ }^{101}$. Revisada la documentación del caso, el Consejo de Inquisición, en sesión de 17 de noviembre de 1704, declaró nulo el proceso contra Díaz. Felipe V decidió también que los casos de los consejeros jubilados y de los votos en el Consejo de Inquisición se habían tratado de manera arbitraria y por lo tanto merecían ser reconsiderados. El rey justificó sus acciones por creer "que únicamente se dirigían al fin del remedio de los abusos y poner en planta un tribunal tan santo" ${ }^{102}$. Los consejeros fueron restituidos y se absolvió a Díaz de todas las calumnias hechos y dichos imputados en la causa "dándole por totalmente inocente y salvo de ellos" ${ }^{103}$ y se lo reintegró en su plaza.

El rey no desaprovechó esta instancia para dejar en claro los límites a la autoridad correspondiente al Inquisidor General ${ }^{104}$ al que se había dirigido el 7 de noviembre de 1704 en estos términos:

Yo el rey a vos el Obispo de Segovia como Inquisidor General: tendréis entendido... que habiéndose de mi orden examinado...que a los Ministros que le componen (El Consejo de Inquisición)... que los habéis de respetar y reconocer... como a ministros y que habéis de tener presente son mis Ministros que representan mi real persona, exerciendo mi jurisdicción territorial y que como a tales los hayan de reconocer y respetar todos los Inquisidores Generales, no embarazándoles de ningún modo el voto decisivo que por derecho les compete y en mi real nombre exercen ${ }^{105}$.

El autor elogia sin disimulo la institución destacando el papel de los consejeros y les recomienda que eviten las malas influencias que siembren la discordia en un organismo que tanto ha hecho por la pureza de la fe ${ }^{106}$.

100 El nuncio había encargado al fiscal de la Suprema, Juan Fernández de Frías (austracista) para responder a Folch de Cardona. GonzÁlez MezQuita, op. cit. (nota 22, 2007), p. 221 y ss.

101 Críticos documentos, op. cit. p. 4. Consulta del Supremo Consejo de Castilla. "Señor. Por Decreto de V. M. de 24 de Diciembre de 1703, se digna mandar reconozca las consultas hechas por el consejo de Inquisición con motivo de los procedimientos del Obispo Inquisidor general así en la causa del Maestro Fr. Froylán Díaz, como de la jubilación de los Ministros de aquel Consejo, creaciones de empleos supernumerarios en perjuicio de la hacienda del Santo Oficio y continuación de Don Juan Joseph de Tejada en el exercicio de su plaza de Consejero después de haver hecho dexación de ella, y que enterado V. M. de todos sus contenidos, y de las demás consultas de diferentes juntas de Ministros que V. M. mandó formar, para que viesen y propusiesen lo que se ofreciese en estas dependencias: Ha resuelto V. M. remitirlo todo al Consejo pleno, para que viéndose en él estas consultas y demás papeles que las acompañan con la entera reflexión que pide su importancia y gravedad, consulte con la mayor claridad y distinción lo que sobre cada punto se le ofreciere y pareciere".

102 Ibidem, p. 21.

103 Proceso criminal, p. 229.

104 LEA, H. C.: Historia de la Inquisición en España, 3 vols., Madrid, FUE, 1983.

105 Proceso criminal, p. 224.

106 Criticos documentos, p. 17. "Pero como siempre el enemigo común ha procurado con todos sus ardides asestar, convatir y desvanecer en España tan sagrado instituto, executandolo con poderosos é indiscretos medios, como fueron emulaciones competencias y otros arbitrios y no lo ha podido lograr su infernal astucia... discurrió vigilante el sembrar cizaña y fomentar la desunión en lo interior de este Santo edificio levantando 
Votando los consejeros de Inquisición (con la misma jurisdicción que el Inquisidor general) todas las causas referidas decisivamente por sus votos, arreglándose la sentencia á la mayor parte, sin que el Inquisidor general haya tenido voto de calidad alguno, como los demás presidentes de consejos y chancillerías según lo dispuesto por nuestras leyes del reyno ${ }^{107}$.

Por su parte, Felipe V pone punto final a la crisis planteada por este conflicto de jurisdicciones, el 27 de abril de 1705 cuando notifica al Consejo su petición al Papa para que no prorrogue la licencia de ausencia de Baltasar de Mendoza para residir fuera de su diócesis y designe a Vidal Marín, obispo de Ceuta como Inquisidor General $^{108}$.

En este análisis del Proceso, ha sido nuestra intención realizar una nueva lectura del documento para llamar la atención sobre cuestiones que han sido abordadas desde el punto de vista de sus implicaciones supersticiosas y políticas pero en pocas ocasiones, a partir de las vertientes jurisdiccionales que se desprenden de su epílogo. Por cierto, existen vinculaciones entre las camarillas cortesanas a finales del reinado de Carlos II y los hechizos o supuestos hechizos sufridos por el rey. Es llamativo que los demonios pudieran tener una inclinación política y realizar acusaciones cruzadas dependiendo de quién fuera el destinatario de las imputaciones ${ }^{109}$.

No podemos dudar del efecto causado en su tiempo por los hechizos que han sido, con frecuencia, objeto de risa para autores extranjeros y criticados como propios de la corte española aunque, en realidad, estas prácticas no fueran ajenas a otras cortes europeas. Parece sensato considerar que "Don Carlos fue entonces víctima de la cultura supersticiosa de su época" 110 . Tampoco dudamos del impacto causado por las medidas del Inquisidor General que le generaron un enfrentamiento con el Consejo de la Inquisición y el Consejo de Castilla que se agravó, cuando intentó llevar su problema a Roma. Al mismo tiempo, comprobamos que los instrumentos discursivos utilizados, en interacción con las prácticas realizadas por las camarillas cortesanas obtuvieron los efectos buscados. Esto se comprueba con motivo del motín de 1699 que tuvo como resultado el exilio de los actores políticos que se señalaban como culpables del malestar y las carestías en ese momento. Lo mismo puede argumentarse en el caso de las acciones seguidas y los argumentos vertidos a propósito del proceso de Froilán Díaz.

No pretendemos dejar zanjada una cuestión que presenta muchas dudas, sólo plantear interrogantes, reformular hipótesis, llamar la atención sobre un tema que ha sido

una discordia civil entre los mismos Ministros, y su cabeza el Presidente para lograr con las mismas armas que le defienden su total ruina".

107 Ibidem, p. 12.

108 López Vela, op. cit. (nota 97, 1988), p. 85.

109 García CÁrcel, R. y Alabrús Iglesias, R. M.: España en 1700 ¿Austrias o Borbones?, Madrid, Alianza, 2001, p. 95.

110 Contreras, op. cit. (nota 15, 2003), p. 300. 
mirado de forma unilateral por algunos o ignorado por otros. Apelando a la multiperspectiva, a la multicausalidad, para explicar procesos históricos a través de la intersección de planos. Encontramos que, detrás de los hechos analizados en el Proceso criminal y los Críticos documentos -en defensa por un lado, de los intereses de los consejeros frente al Inquisidor General y del poder real por otro, frente a jurisdicciones internas y externas- existe un zócalo que atraviesa el relato y que presenta un tema de jurisdicciones y campos de poder.

Por una parte, se manifiestan las intenciones del Nuncio que planteaba que el conflicto entre el Inquisidor y los consejeros era un problema que involucraba a eclesiásticos y merecía por eso la intervención del Papa por estar dentro de la jurisdicción Apostólica. Por otra, se ponen en evidencia los argumentos de Lorenzo Folch para demostrar que, si bien esto era cierto, el Inquisidor General era Presidente de un Consejo Real y por eso, vasallo del rey igual que el resto de los integrantes de la Inquisición. Por estas razones Folch considera que el rey puede intervenir para pacificar estas relaciones y recomienda al nuncio:

Proceder con mas precauciones que hasta aquí, en las proposiciones que sienta, y firma porque las comprehenden los Ministros del Rey de España y conocen que camina su Ilustrísisma con el fin de despojar a S, M. de sus mas especiosas regalías así en el conocimiento de las fuerzas como en el uso de la económica potestad ${ }^{111}$.

Folch, supuesto autor del Proceso, al alentar a los Consejeros de la Suprema a no dar su acuerdo a los deseos del Inquisidor General Mendoza, no sólo defiende la autoridad del Consejo, sino que pone en duda la superioridad del voto del Inquisidor. Pero esta argumentación tiene una intencionalidad más profunda pues, además de anular las pretensiones autoritarias del Inquisidor, defiende la autoridad real frente a la posibilidad de intervención papal para dirimir las cuestiones jurisdiccionales planteadas. El enfrentamiento mostraba una pugna por controlar por un lado y defender por otro la supremacía e independencia del Inquisidor General en el gobierno de la Inquisición respecto al Consejo de la Suprema y frente a los vínculos directos que mantenía con Roma ${ }^{112}$.

Por su parte, el rey en su decreto resolvía la discusión sobre la posición de los integrantes de la Inquisición declarándolos ministros reales y negando la pretensión del Inquisidor General al voto decisivo. Mendoza capituló ante la amenaza real de la ocupación de temporalidades y destierro fuera de España. En este sentido, comprobamos la afirmación del poder real frente a posibles injerencias del Papa y a problemas de jurisdicción interna ${ }^{113}$.

Años más tarde, otro Folch de Cardona, en este caso Antonio, mostraría las aristas cambiantes del enfrentamiento entre los poderes eclesiásticos y el Monarca, esta vez manifestando su oposición a la extensión del poder real en función de los resultados de la Guerra de Sucesión, propuesta por Macanaz. Antonio Folch de Cardona se opondría a la confiscación de los bienes eclesiásticos de quienes habían sostenido al

\footnotetext{
111 Proceso criminal, p. 191.

112 Torres ArCe, op. cit., (nota 96, 2006), p. 28.

113 Monod, op. cit. (nota 4, 2001), p. 339.
} 
pretendiente austríaco. Asignaba a la Iglesia un papel que pretendía mantenerla como actor esencial de la vida política, aspirando a circunscribir el poder del rey. El regalismo pondría de manifiesto vertientes internas y externas de un proceso en el que las instituciones del reino serían puestas a prueba en conflictos permanentes ${ }^{114}$.

\footnotetext{
114 DEDIEU, J-P.: Après le Roi. Essai sur l'effondrement de la monarchie espagnole. Madrid, Casa de Velázquez, 2010, p. 47.
} 